\title{
Learning the lessons of antitumour necrosis factor therapy-associated psoriasis
}

\author{
Matt Shale MRCP ${ }^{1}$, Subrata Ghosh MD FRCP FRCPE FRCPC ${ }^{2}$
}

M Shale, S Ghosh. Learning the lessons of antitumour necrosis factor therapy-associated psoriasis. Can J Gastroenterol 2009;23(10):674-676.

Psoriasis or psoriasiform skin lesions, as an adverse effect of treatment with antitumor necrosis factor antibody therapy, have been described relatively recently. Patients with these lesions have no personal or family history of psoriasis. In a small number of cases, an association with Chlamydia has been suggested. The skin lesions may disappear on discontinuation of therapy or, in the majority of cases, even if antitumor necrosis factor antibody therapy is continued. Therefore, withdrawal of therapy is generally not required for this adverse effect but referral to a dermatologist may be desirable for confirmation of diagnosis and treatment.

Key Words: Adverse effects; Antitumour necrosis factor antibodies; Biological therapy; Psoriasis

The development of biological therapies targeting tumour 1 necrosis factor (TNF)-alpha has revolutionized the management of a wide variety of inflammatory diseases including rheumatoid arthritis (RA), ankylosing spondylitis, psoriasis and psoriatic arthritis, and the inflammatory bowel diseases (IBDs) Crohn's disease and ulcerative colitis. Although initial safety concerns centred on the risk of infective or malignant complications of these agents, clinical experience has demonstrated that with appropriate patient selection and screening before use, they have an acceptable safety profile in this regard compared with other immunomodulatory drugs or corticosteroids (1-3).

However, with growing experience in the use of biological drugs, it has become clear that the manipulation of very tightly defined pathways or molecules may be associated with less easily predicted, highly specific adverse events compared with traditional immunomodulatory therapies. This is exemplified by the increased risk of JC virus-associated progressive multifocal leukoencephalopathy in patients treated with the alpha-4 integrin inhibitor natalizumab (4) and the association of tuberculosis or hepatosplenic T cell lymphoma with antiTNF therapy $(5,6)$.

Recently, many reports of psoriasis or psoriasiform skin lesions in patients receiving anti-TNF therapy have appeared (7-13), suggesting that this also may be a highly specific adverse effect of this class of drugs. However, in contrast with the two previously cited examples, psoriasis is neither associated with a known infective etiology or a malignant process. Furthermore, anti-TNF treatment is effective in the management of severe refractory psoriasis (14) and in the development or exacerbation of the disease - a paradox to individuals receiving these

\section{Tirer des leçons du psoriasis associé au traitement du facteur de nécrose antitumorale}

Il est relativement récent que le psoriasis ou les lésions cutanées psoriasiformes, une manifestation d'effet indésirable d'une thérapie aux anticorps du facteur de nécrose antitumorale, est décrit. Les patients ayant ces lésions n'ont pas d'antécédents personnels ou familiaux de psoriasis. Dans quelques cas, on a suggéré la possibilité d'une association avec le Chlamydia. Les lésions cutanées peuvent disparaître à l'arrêt du traitement ou, dans la majorité des cas, malgré la poursuite du traitement. C'est pourquoi il n'est généralement pas nécessaire d'interrompre le traitement en présence de cet effet indésirable, mais il peut être souhaitable d'aiguiller le patient vers un dermatologue afin de confirmer le diagnostic et le traitement. drugs. While psoriasis is unquestionably a less severe adverse event than progressive multifocal leukoencephalopathy or hepatosplenic T cell lymphoma, it appears to be significantly more common. The generally less severe nature of the condition also poses questions regarding the safety of the continuation or need for cessation of therapy, which are not issues with life-threatening events. An expanding literature of experience with anti-TNF-associated psoriasis is providing abundant information, with implications for the use of these drugs by gastroenterologists.

The first published report of this association appeared in 2004 (7), and concerned the development of symmetrical psoriasiform plaques in a patient with Crohn's disease treated with infliximab. Since this initial report, cases have been noted within clinical trials, biological treatment registries and routine practice, with 199 cases now documented in various levels of detail (7-14). The frequency of this adverse event noted within clinical trials has been as high as 3\% (8); however, a United Kingdom registry study of biologic-treated RA patients estimated a more conservative overall rate of one case per 1000 patient years of treatment (13). Psoriasis or psoriasiform lesions have been observed in association with three licensed anti-TNF drugs (the monoclonal antibodies infliximab and adalimumab, and the TNF-receptor fusion protein etanercept), although it appears to be more common in individuals receiving the more potent monoclonal antibodies. Case reports of patients receiving treatment for diverse indications including RA, ankylosing spondylitis, IBD and psoriasis or psoriatic arthritis have been published. The interval between the introduction of treatment and the appearance of skin disease is highly variable, but most

${ }^{1}$ Gastroenterology Section, Imperial College London, Hammersmith Hospital, London, United Kingdom; ${ }^{2}$ University of Calgary, Calgary, Alberta

Correspondence: Dr Subrata Ghosh, Division of Gastroenterology, University of Calgary, Teaching Research and Wellness Centre,

6th Floor, 3280 Hospital Drive Northwest, Calgary, Alberta T2N 4N1. Telephone 403-592-5010, fax 403-592-5080, e-mail ghosh@ucalgary.ca

Received for publication January 14, 2009. Accepted January 15, 2009 
commonly occurs within two to six months $(12,13)$. Plaque, guttate and pustular psoriasis have all been noted; however, palmoplantar pustular disease appears to be somewhat more common than in idiopathic psoriasis, accounting for up to $50 \%$ of reported cases $(10,11)$. Although some patients developing this adverse effect were known to have psoriasis before treatment, many had no personal or family history of the disease. In patients with a previous diagnosis of psoriasis, the morphology of disease occurring in association with anti-TNF therapy is often discordant (11). Skin biopsies performed in a substantial number of cases generally confirmed the typical histological features of psoriasis.

In view of the proven efficacy of anti-TNF drugs in treating psoriasis, how can this apparently paradoxical association be explained? Because the majority of cases have occurred in patients with rheumatological conditions, some authors have questioned whether they simply represent misdiagnosed cases of psoriatic arthritis that initially presented without skin manifestations and subsequently developed cutaneous disease. Alternatively, psoriasis is not an uncommon condition (affecting $2.5 \%$ of the United Kingdom population) and it is possible that these cases are merely coincidental in their onset near the time of introduction of anti-TNF therapy. Indeed, psoriasis may actually be more common in patients with conditions such as IBD (up to $10 \%$ ) (15). However, the strong temporal relationship of treatment initiation to disease onset and the particular preponderance of pustular disease suggest this is unlikely to be the explanation. Even more convincingly, cases of prompt resolution of psoriasis on treatment withdrawal and positive rechallenge experience suggest a direct causal link.

Although such delayed onset is unusual, the clinical pattern is otherwise reminiscent of a conventional drug reaction. While skin biopsy in the majority of cases confirms features of psoriasis, some have noted atypical findings supporting the concept that such lesions actually represent a psoriasiform drug reaction (16). Furthermore, patch testing with topically applied anti-TNF drugs was reported to reproduce histologically comparable skin lesions following the occurrence of anti-TNF-associated psoriasis in four of eight patients investigated (17). However, such a theory would not adequately explain cases in which skin disease continues after treatment withdrawal, or those that recur when using a different anti-TNF drug.

Psoriasiform lesions are known to occur as a reactive phenomenon to remote infection (18). Although infective triggers were sought and excluded in many reported cases, it is plausible that subclinical infection in the setting of anti-TNF therapy may have triggered the condition. Specific palmoplantar psoriasiform lesions, indistinguishable from psoriasis, also occur in keratoderma blenorrhagicum, commonly secondary to chlamydial infection. In a series of three patients with suspected anti-TNF-associated psoriasis, Chlamydia trachomatis was detected within skin lesions by polymerase chain reaction assays, leading to the suggestion that, at least in some patients, anti-TNF-associated psoriasiform lesions are actually keratoderma blennorrhagicum (19). As with mycobacteria, Chlamydia species may cause persistent asymptomatic infection, with TNF playing a critical role in controlling and limiting its replication (20).

Alternatively, despite its clear, overall pro-inflammatory effects, it is well recognized that blocking TNF-alpha may actually favour specific autoimmune phenomena, including autoantibody formation, lupus-like reactions and vasculitis. Anti-TNF therapy may activate autoreactive T cells (21), and of particular relevance to the skin, may upregulate interferon (IFN)-alpha activity (22). Observations in animal models and human disease increasingly implicate IFN-alpha as a key mediator in early psoriatic lesions (23), which are a recognized adverse effect of recombinant IFN-alpha therapy (24,25). Studies in anti-TNF-associated psoriasis show greater upregulation of IFN-alpha within skin plaques than in idiopathic disease (26). Immunologically, this is not unexpected because TNF-alpha is known to negatively regulate the maturation and function of plasmacytoid dendritic cells - the major source of type I IFNs, including IFN-alpha $(22,23)$. Therapeutic inhibition of TNF-alpha signalling - resulting in derepression of this pathway - would increase IFN-alpha activity and could trigger psoriasis in susceptible individuals. Of note, established psoriatic lesions are characterized by enhanced sensitivity to IFNalpha rather than persistently increased cytokine levels, which may explain why some cases of anti-TNF-induced disease persist despite the withdrawal of TNF inhibition (23). Why certain individuals are more susceptible to this than others is not clear, but differential levels of other regulating cytokines or a genetically determined sensitivity to specific cytokines may be relevant. The finding that patients developing palmoplantar pustulosis have reduced palmar sweat duct TNF activity supports this idea (27).

While the mechanisms of anti-TNF-associated psoriasis are being clarified, how should a patient developing the condition be managed? A number of approaches have been reported including continuation of treatment (usually with conventional psoriasis therapy), switching to an alternative anti-TNF agent or complete withdrawal of the entire class of drugs. Due to the uncontrolled nature of data published in case reports, the optimal strategy is difficult to define; however, certain points should be considered $(10,11)$ :

- skin disease may improve or resolve in more than two-thirds of patients who simply continue anti-TNF therapy;

- in patients who stop treatment, persistent disease occurs in less than 5\%; and

- up to $10 \%$ of patients whose skin condition is improved by stopping anti-TNF medication will develop recurrent disease if treated again with the same drug or an alternative antiTNF agent.

Ultimately, decisions need to be based on individual circumstances, including the extent and severity of skin disease, as well as the efficacy of the TNF agent in treating the condition for which it was initiated and the availability of realistic therapeutic alternatives. The majority of patients can be reassured that developing psoriasis while on anti-TNF therapy does not mandate withdrawal of treatment, nor is it necessarily associated with an adverse prognosis. Some patients improve without specific treatment of their skin disease; however, referral to a dermatologist for consideration of skin biopsy and specialist treatment is appropriate, particularly if anti-TNF treatment is to be continued.

Recognition of this association has wider implications. For dermatologists, it provides an in vivo demonstration of the effects of altered IFN-alpha signalling, potentially offering new 
therapeutic horizons. However, it is the demonstration of another unpredicted and highly specific adverse effect associated with potent biological therapy that is surely the most important lesson here. Large numbers of such therapies are under development and are likely to become available shortly for conditions that include IBD. Specific risks may appear only after very large numbers of patients have been exposed or within certain patient groups. Vigilance for these adverse events, even those that appear paradoxical, will not only optimize the safety of such treatments, but may offer unexpected insights into disease pathogenesis.

\section{REFERENCES}

1. Lichtenstein GR, Feagan BG, Cohen RD, et al. Serious infections and mortality in association with therapies for Crohn's disease: TREAT registry. Clin Gastroenterol Hepatol 2006;4:621-30.

2. Fidder HH, Schnitzler F, Ferrante M, et al. Long-term safety of infliximab for the treatment of inflammatory bowel disease: A single center cohort study. Gut 2009;58:501-8.

3. Toruner M, Loftus EV Jr, Harmsen WS, et al. Risk factors for opportunistic infections in patients with inflammatory bowel disease. Gastroenterology 2008;134:929-36.

4. Van Assche G, Van Ranst M, Sciot R, et al. Progressive multifocal leukoencephalopathy after natalizumab therapy for Crohn's disease. N Engl J Med 2005;353:362-8.

5. Shale M, Kanfer E, Panaccione R, Ghosh S. Hepatosplenic T cell lymphoma in inflammatory bowel disease. Gut 2008;57:1639-41.

6. Keane J, Gershon S, Wise RP, et al. Tuberculosis associated with infliximab, a tumor necrosis factor-alpha neutralizing agent. N Engl J Med 2001;345:1098-104.

7. Verea MM, Del Pozo J, Yebra-Pimentel MT, et al. Psoriasiform eruption induced by infliximab. Ann Pharmacother 2004;38:54-7.

8. Baeten D, Kruithof E, Van den Bosch F, et al. Systematic safety follow up in a cohort of 107 patients with spondyloarthropathy treated with infliximab: A new perspective on the role of host defence in the pathogenesis of the disease? Ann Rheum Dis 2003;62:829-34.

9. Collamer AN, Guerrero KT, Henning JS, Battafarano DF. Psoriatic skin lesions induced by tumor necrosis factor antagonist therapy: A literature review and potential mechanisms of action. Arthritis Rheum 2008;59:996-1001.

10. Wollina U, Hansel G, Koch A, et al. Tumor necrosis factor-alpha inhibitor-induced psoriasis or psoriasiform exanthemata: First 120 cases from the literature including a series of six new patients. Am J Clin Dermatol 2008;9:1-14.

11. Mössner R, Thaci D, Mohr J, et al. Manifestation of palmoplantar pustulosis during or after infliximab therapy for plaque-type psoriasis: Report on five cases. Arch Dermatol Res 2008;300:101-5.
12. Wendling D, Balblanc JC, Briançon D, et al. Onset or exacerbation of cutaneous psoriasis during TNF-alpha antagonist therapy. Joint Bone Spine 2008;75:315-8.

13. Harrison MJ, Dixon WG, Watson KD, et al. Rates of new-onset psoriasis in patients with rheumatoid arthritis receiving antiTNF-alpha therapy. Results from the British Society for Rheumatology Biologics Register. Ann Rheum Dis 2009;68:209-15.

14. Gottlieb AB, Evans R, Li S, et al. Infliximab induction therapy for patients with severe plaque-type psoriasis: A randomized, double-blind, placebo-controlled trial. J Am Acad Dermatol 2004;51:534-42.

15. Yates VM, Watkinson G, Kelman A. Further evidence for an association between psoriasis, Crohn's disease and ulcerative colitis. Br J Dermatol 1982;106:323-30.

16. Seneschal J, Lepreux S, Bouyssou-Gauthier ML, et al. Psoriasiform drug eruptions under anti-TNF treatment of arthritis are not true psoriasis. Acta Derm Venereol 2007;87:77-80.

17. Seneschal J, Lepreux S, Milpied B, Schaeverbeke T, Taïeb A. Psoriasiform eruptions during anti-TNF-alpha treatment: Psoriasis or not? Arch Dermatol 2007;143:1593-5.

18. Fry L, Baker BS. Triggering psoriasis: The role of infections and medications. Clin Dermatol 2007;25:606-15.

19. Carter JD, Gerard HC, Hudson AP. Psoriasiform lesions induced by tumour necrosis factor antagonists: A skin-deep medical conundrum. Ann Rheum Dis 2008;67;1181-3.

20. Inman RD, Chiu B. Early cytokine profiles in the joint define pathogen clearance and severity of arthritis in Chlamydia-induced arthritis in rats. Arthritis Rheum 2006;54:499-507.

21. Cope A, Ettinger R, McDevitt H. The role of TNFa and related cytokines in the development and function of the autoreactive T cell repertoire. Res Immunol 1997;148:307-12.

22. Palucka AK, Blanck JP, Bennett L, Pascual V, Banchereau J. Cross-regulation of TNF and IFN-alpha in autoimmune diseases. Proc Natl Acad Sci USA 2005;102:3372-7.

23. Nestle FO, Conrad C, Tun-Kyi A, et al. Plasmacytoid predendritic cells initiate psoriasis through interferon-alpha production. J Exp Med 2005;202:135-43.

24. Taylor C, Burns D, Wiselka M. Extensive psoriasis induced by interferon alpha treatment for chronic hepatitis C. Postgrad Med J 2000;76:365-7.

25. Ketikoglou I, Karatapanis S, Elefsiniotis I, Kafiri G, Moulakakis A. Extensive psoriasis induced by pegylated interferon alpha-2b treatment for chronic hepatitis B. Eur J Dermatol 2005;15:107-9.

26. de Gannes GC, Ghoreishi M, Pope J, et al. Psoriasis and pustular dermatitis triggered by TNF- $\alpha$ inhibitors in patients with rheumatologic conditions. Arch Dermatol 2007;143:223-31.

27. Michaelsson G, Kajermo U, Michaelsson A, Hagforsen E. Infliximab can precipitate as well as worsen palmoplantar pustulosis: Possible linkage to the expression of tumour necrosis factor-alpha in the normal palmar eccrine sweat duct? Br J Dermatol 2005;153:1243-4. 


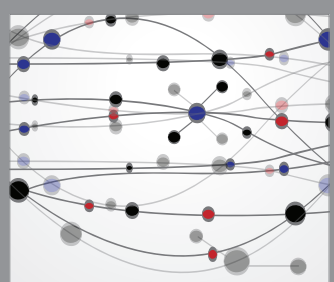

The Scientific World Journal
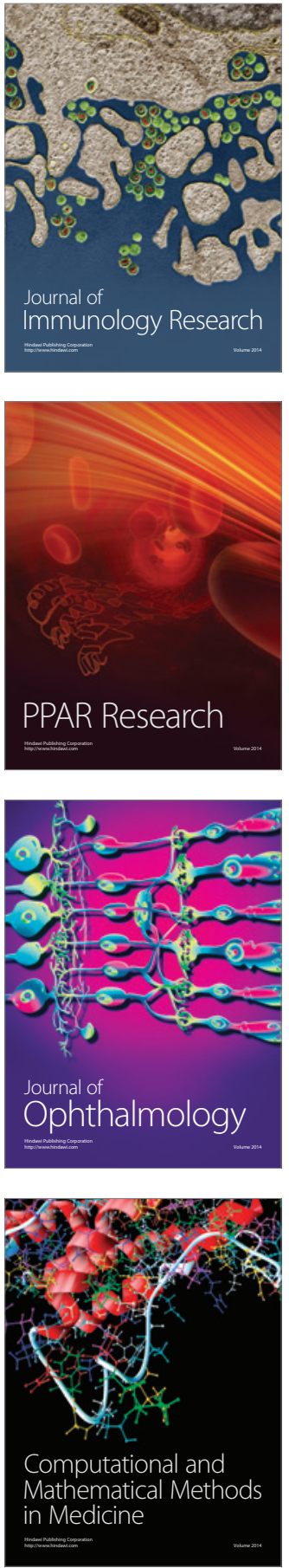

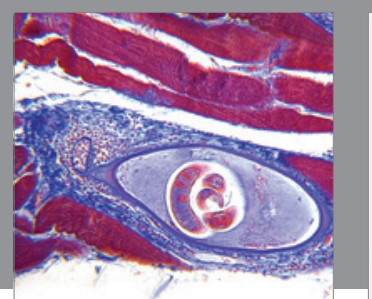

Gastroenterology Research and Practice

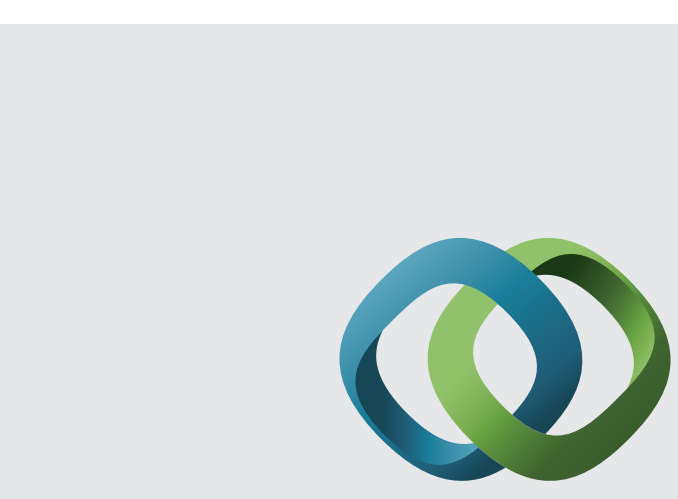

\section{Hindawi}

Submit your manuscripts at

http://www.hindawi.com
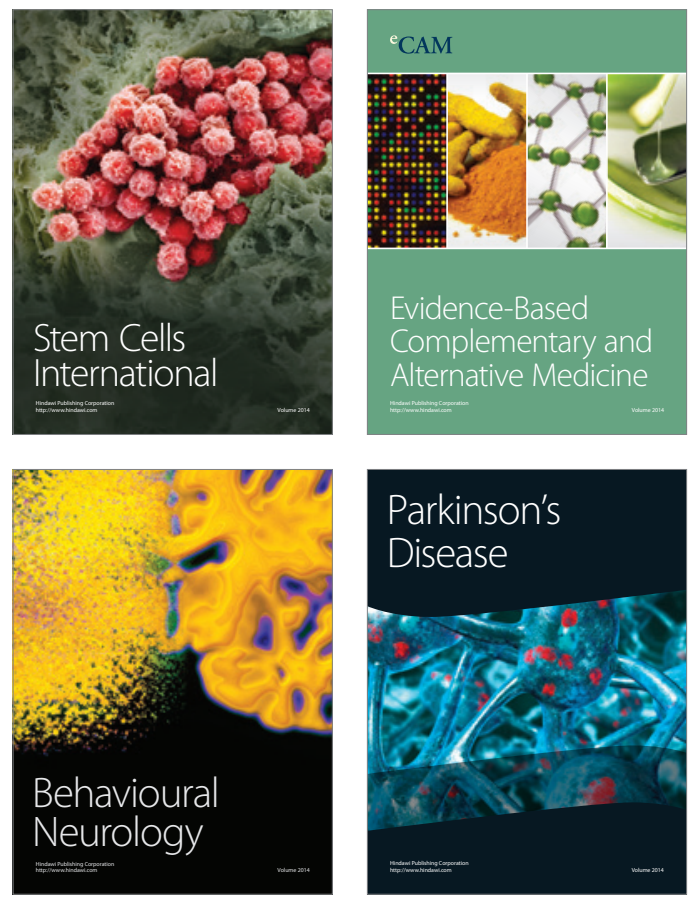
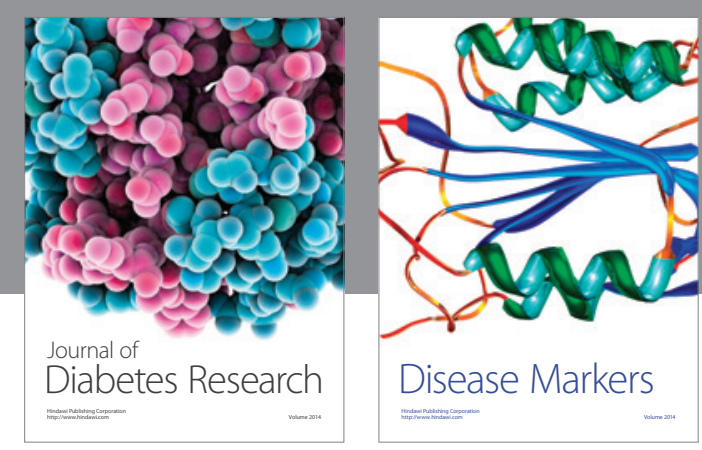

Disease Markers
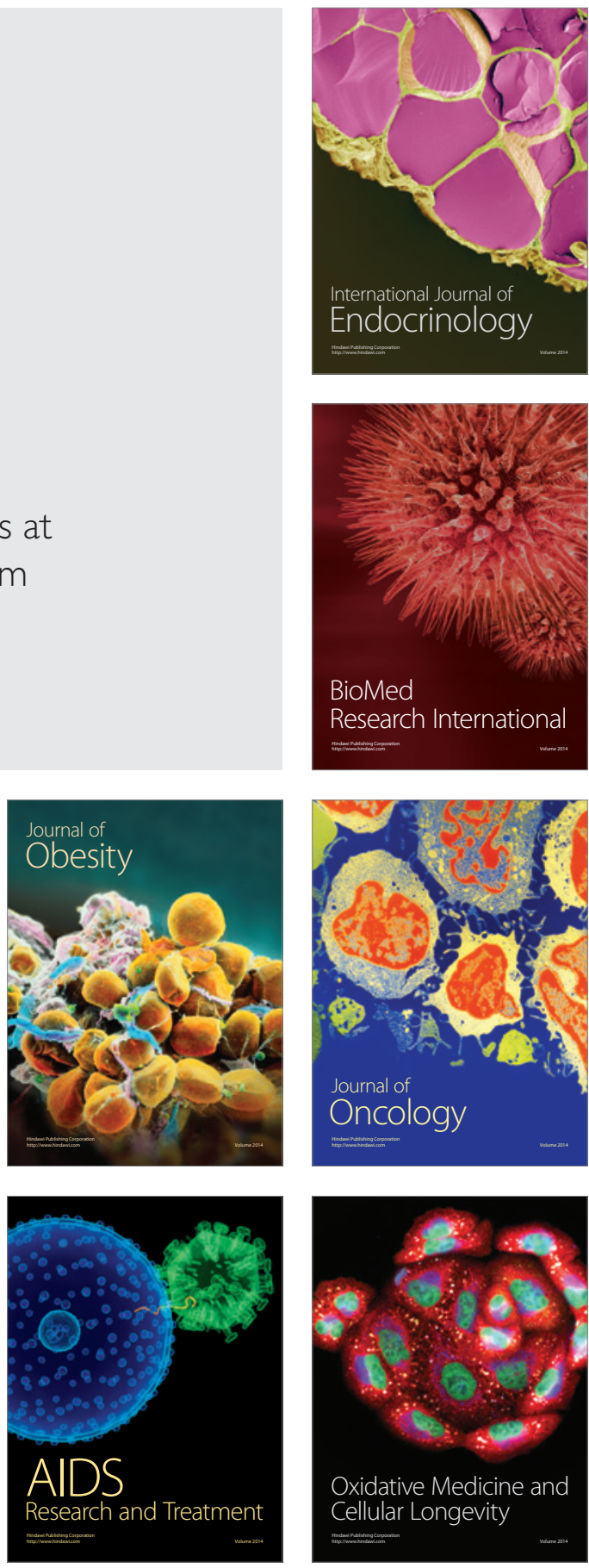